\section{Role of Arginine Vasopressin and Angiotensin II in Cardiovascular Responses to Combined Acute Hypoxemia and Hypercapnic Acidosis in Conscious Dogs}

C. Edward Rose, Jr., Richard L. Godine, Jr., Karren Y. Rose, Robert J. Anderson, and Robert M. Carey Department of Internal Medicine, University of Virginia School of Medicine, Charlottesville, Virginia 22908; Department of Internal Medicine, University of Colorado Health Sciences Center, Denver, Colorado 80262 bstract. The physiological relationship of increased circulating angiotensin II and vasopressin to circulatory changes during combined hypoxemia and hypercapnic acidosis is unclear. To evaluate the role(s) of angiotensin II and vasopressin, seven unanesthetized female mongrel dogs with controlled sodium intake $(80$ $\mathrm{meq} / 24 \mathrm{~h} \times 4 \mathrm{~d}$ ) were studied during $40 \mathrm{~min}$ of combined acute hypoxemia and hypercapnic acidosis $\left(\mathrm{PaO}_{2}, 36 \pm 1\right.$ $\mathrm{mmHg} ; \mathrm{PaCO}_{2}, 55 \pm 2 \mathrm{mmHg} ; \mathrm{pH}=7.16 \pm 0.04$ ) under the following conditions: $(a)$ intact state with infusion of vehicles alone; $(b)$ beta-adrenergic blockade with infusion of $d, l$-propranolol $(1.0 \mathrm{mg} / \mathrm{kg}$ bolus, $0.5 \mathrm{mg} / \mathrm{kg}$ per $\mathrm{h}$ ); (c) vasopressin pressor antagonism by the administration of the vasopressin pressor antagonist $d$ $\left(\mathrm{CH}_{2}\right)_{5} \mathrm{Tyr}($ methyl)arginine-vasopressin $(10 \mu \mathrm{g} / \mathrm{kg})$; and (d) simultaneous vasopressin pressor and angiotensin II inhibition with the additional infusion of 1-sarcosine, 8-alanine angiotensin II $(2.0 \mu \mathrm{g} / \mathrm{kg}$ per $\mathrm{min})$. The rise in mean arterial pressure during the combined blood-gas derangement with vehicles appeared to be related to increased cardiac output, since total peripheral resistance fell. Beta-adrenergic blockade abolished the fall in total peripheral resistance and diminished the rise in cardiac output during combined hypoxemia and hypercapnic acidosis, but the systemic pressor response was unchanged. In addition, the rise in mean arterial pressure during the

\footnotetext{
Address reprint requests to Dr. Rose, Pulmonary Division, University of Virginia Medical Center.

Received for publication 7 November 1983 and in revised form 14 February 1984.
}

J. Clin. Invest.

(C) The American Society for Clinical Investigation, Inc.

0021-9738/84/08/0321/11 $\$ 1.00$

Volume 74, August 1984, 321-331 combined blood-gas derangement was unaltered with vasopressin pressor antagonism alone. In contrast, the simultaneous administration of the vasopressin pressor and angiotensin II inhibitors during combined hypoxemia and hypercapnic acidosis resulted in the abrogation of the overall systemic pressor response despite increased cardiac output, owing to a more pronounced fall in total peripheral resistance. Circulating catecholamines were increased during the combined blood-gas derangement with vasopressin pressor and angiotensin II blockade, suggesting that the abolition of the systemic pressor response in the last $30 \mathrm{~min}$ of combined hypoxemia and hypercapnic acidosis was not related to diminished activity of the sympathetic nervous system. These studies show that vasopressin and angiotensin II are major contributors to the systemic pressor response during combined acute hypoxemia and hypercapnic acidosis.

\section{Introduction}

Compensatory processes maintain circulatory function in healthy human subjects during acute hypoxemia $(1,2)$, acute hypercapnic acidosis (3), and combined hypoxemia and hypercapnic acidosis (4). The maintenance of circulatory homeostasis also was evident in recent laboratory observations in unanesthetized dogs with increased mean arterial pressure during acute hypoxemia or acute hypercapnic acidosis (5). In addition, the combination of acute hypoxemia and hypercapnic acidosis led to further increases in mean arterial pressure, but renal hemodynamic function decreased (5). Despite the evidence of circulatory homeostasis during acute hypoxemia and/or hypercapnic acidosis from these clinical and laboratory experiments, the specific mechanisms for compensatory processes have not yet been elucidated.

The sympathetic nervous system has been heralded as having a major role in maintaining circulatory homeostasis during acute 
hypoxemia (6) and acute hypercapnic acidosis (7), based on observations in anesthetized dogs. Evidence of sympathetic nervous system activation is provided by recent observations of increased circulating catecholamines during acute hypoxemia and hypercapnic acidosis in unanesthetized dogs (8). However, a central role for the sympathetic nervous system in circulatory homeostasis can be questioned in view of previous observations that the systemic vascular responses to exogenous catecholamines are diminished during acute hypoxemia (9) and hypercapnic acidosis (10). Moreover, recent laboratory investigations in dogs reveal that other circulating pressor substances are increased during acute hypoxemia and hypercapnic acidosis and may contribute to systemic or renal vasoconstriction; these substances include angiotensin II (5) and vasopressin (11).

We have previously demonstrated an important role for the renin-angiotensin system in cardiovascular regulation during combined hypoxemia and hypercapnic acidosis (5). The present study was designed to investigate the effects of vasopressin blockade and simultaneous vasopressin and angiotensin II blockade during acute hypoxemia and hypercapnic acidosis in unanesthetized dogs. This was accomplished by the use of specific antagonists of the vascular effects of vasopressin and angiotensin II.

The present experiments suggest that the systemic pressor response during combined hypoxemia and hypercapnic acidosis is a balance of multiple effects of the sympathetic nervous system, angiotensin II, and vasopressin. When intact, angiotensin II and vasopressin limit the fall in total peripheral resistance during the combined blood-gas derangement, such that the rise in cardiac output mediated by the sympathetic nervous system predominates, and mean arterial pressure increases.

\section{Methods}

Animal preparation. Studies were performed in seven unanesthetized female mongrel dogs who weighed from 18.4 to $27.9 \mathrm{~kg}$. During pentobarbital anesthesia $(30 \mathrm{mg} / \mathrm{kg}$, i.v.) each animal underwent preparatory surgery with sterile technique, which consisted of carotid artery exteriorization into a carotid loop, tracheostomy, and splenectomy, at least 4 wk before study. The splenectomy was performed to abolish any increase in hematocrit during the acute blood-gas derangements, as has been observed in anesthetized animals during hypercapnic acidosis (12). All animals recovered completely and were not studied in any protocol for at least $4 \mathrm{wk}$.

Before study, each animal was placed on a constant sodium intake of $80 \mathrm{meq} / 24 \mathrm{~h}$ for $4 \mathrm{~d}$ before study. This was accomplished by the daily administration of $500 \mathrm{ml}$ of $0.9 \%$ sodium chloride $(75 \mathrm{meq})$ in travenously and by a diet that contained less than 5 meq sodium $(\mathrm{h} / \mathrm{d}$; Hills Prescription Diet, Div. Riviana Foods, Topeka, KS).

On the morning of study, catheters were inserted in the urinary bladder (18F; Travenol Laboratories, Inc., Baxter Travenol Laboratories, Deerfield, IL), carotid loop (18 gauge; Becton-Dickinson and Co., Rutherford, NJ), and superior vena cava (PE 160; Clay Adams Div., BectonDickinson and Co., Parsippany, NJ) via the right external jugular vein. The vascular catheters were inserted by the use of sterile technique and intradermal lidocaine anesthesia. The animals were positioned in a Pavlovian sling, and an infusion was begun at $0.5 \mathrm{ml} / \mathrm{min}$ of $5 \%$ dextrose in water (D5W) ${ }^{1}$ containing concentrations of inulin (Fisher Scientific Co., Fairlawn, NJ) and p-aminohippurate (Merck, Sharp, and Dohme Div., Merck and Co., West Point, PA) to establish and maintain blood levels $15-20 \mathrm{mg} / \mathrm{dl}$ and $1-3 \mathrm{mg} / \mathrm{dl}$, respectively. A tracheostomy tube (8.5 mm I.D.; Portex, Woburn, MA) was inserted and the cuff was inflated to divert all respirable gas. Acute hypoxemia and hypercapnic acidosis were induced simultaneously by the addition of enough $\mathrm{N}_{2}$ and $\mathrm{CO}_{2}$ to the inspired air to reduce the end-tidal oxygen fraction $\left(\mathrm{F}_{\mathrm{E}} \mathrm{O}_{2}\right)$, measured by a fuel cell oxygen analyzer (Applied Technical Products, Denver, $\mathrm{CO}$ ), to 0.07 , and to increase the end-tidal carbon dioxide fraction $\left(\mathrm{F}_{\mathrm{E}} \mathrm{CO}_{2}\right)$, measured by an infrared $\mathrm{CO}_{2}$ analyzer $\left(\mathrm{LB}_{2} ;\right.$ Beckman Instruments, Inc., Fullerton, $\mathrm{CA}$ ), to 0.085 .

\section{Protocols}

Effects of combined acute hypoxemia and hypercapnic acidosis in conscious animals. The protocols were begun after $1 \mathrm{~h}$ of equilibration in the Pavlovian sling and after documentation of stable urine flow. Measurements were obtained over two consecutive 20-min control periods (0-40 $\mathrm{min})$. This was followed by a 5 -min intermediate period (40-45 min) in which either the vasopressin antagonist or vehicle was administered, and either the angiotensin antagonist infusion or vehicle was begun. The combined stimulus of acute hypoxemia and acute hypercapnic acidosis was then induced for two consecutive 20-min periods (45-85 $\mathrm{min}$ ). After measurements during combined hypoxemia and hypercapnic acidosis were completed, the degree of angiotensin II inhibition was assessed by the systemic pressor response to an intravenous injection of angiotensin I, 1,000 ng (Beckman Biochemicals, Palo Alto, CA). It has previously been shown that acute hypoxemia diminishes the activity of angiotensin I-converting enzyme in endothelial cell culture (13). The systemic pressor response was determined with angiotensin I rather than angiotensin II to document an intact renin-angiotensin system after 40min of the combined blood-gas derangement with vehicles alone. Postcontrol measurements were obtained during two 20-min periods $40 \mathrm{~min}$ after the cessation of the blood-gas derangement (125-165 min). After postcontrol measurements, the degree of vasopressin pressor blockade was assessed by the systemic pressor response to an intravenous injection of arginine vasopressin, $20 \mathrm{mU} / \mathrm{kg}$ (Pitressin; Parke, Davis and Co., Morris Plains, NJ). Each dog served as its own control and was studied in the following four protocols, performed no more frequently than every 2 wk.

Protocol I: combined acute hypoxemia and hypercapnic acidosis during infusion of vehicles alone $(n=6)$. This protocol was performed to determine the effects of the combined stimulus in the presence of the angiotensin and vasopressin inhibitor vehicles. These control studies have, in part, been previously reported for five of the animals (5). After control measurements were made, an infusion of the angiotensin inhibitor vehicle (D5W) at $0.5 \mathrm{ml} / \mathrm{min}$ was instituted at the onset of the intermediate period and continued through the combined stimulus (40-85 $\mathrm{min})$. In addition, the acetate/acetic acid vehicle for the vasopressin antagonist was injected as an intravenous bolus over 5 min during the intermediate period (40-45 $\mathrm{min})$. The acetic acid vehicle for the vasopressin antagonist was titrated to $\mathrm{pH} 6.5$ with sodium hydroxide and pH meter (Corning 125; Corning Medical and Scientific, Medfield, MA) just before injection. This resulted in the administration of $0.53 \pm 0.03$ meq $(0.02 \pm 0.002 \mathrm{meq} / \mathrm{kg})$ of the salt of acetic acid diluted in $20 \mathrm{ml}$

1. Abbreviations used in this paper: D5W, $5 \%$ dextrose in water; $d$ $\left(\mathrm{CH}_{2}\right)_{5} \mathrm{Tyr}(\mathrm{Me}) \mathrm{AVP}$, [1-( $\beta$-mercapto- $\beta, \beta$-cyclopentamethylenepropionic acid), 2-(O-methyl)tyrosine]arginine-vasopressin; [Sar ${ }^{1}$, Ala $\left.^{8}\right]$-AII, 1-sarcosine, 8-alanine angiotensin II. 
D5W. The calculated total $\left[\mathrm{H}^{+}\right]$administration with injection of this vehicle was $6 \mathrm{nmol}$. In the intact state without angiotensin or vasopressin blockade, intravenous injection of angiotensin I, $1,000 \mathrm{ng}$, or arginine vasopressin, $20 \mathrm{mU} / \mathrm{kg}$, resulted in systemic pressor responses $(P<0.05)$ of $18 \pm 3$ and $19 \pm 4 \mathrm{mmHg}$, respectively (Fig. 1).

Protocol II: combined acute hypoxemia and hypercapnic acidosis during beta-adrenergic blockade with d,l-propranolol $(n=5)$. To assess the role of the beta-adrenergic system, five dogs were studied during combined hypoxemia and hypercapnic acidosis with beta-adrenergic blockade. Four of these animals were also studied in protocol I. Betaadrenergic blockade was induced with an intravenous bolus injection of $d, l$-propranolol hydrochloride (Sigma Chemical Co., St. Louis, MO), $1.0 \mathrm{mg} / \mathrm{kg}$ in $20 \mathrm{ml} \mathrm{D} 5 \mathrm{~W}$, in the intermediate period (40-45 min) and with an intravenous infusion of $d, l$-propranolol, $0.5 \mathrm{mg} / \mathrm{kg}$ per $\mathrm{h}$ in D5W at $0.5 \mathrm{ml} / \mathrm{min}$, during the intermediate and combined blood-gas derangement periods (40-85 min). The acetic acid vehicle was not administered. This propranolol regimen has previously been shown to abolish the chronotropic response to intravenous injection of the betaadrenergic agonist isoproterenol in anesthetized dogs (14). The degree of beta-adrenergic blockade was assessed by blockade of the increase in heart rate with an intravenous injection of the beta-agonist isoproterenol hydrochloride (Breon Laboratories, Inc., New York, NY), $0.1 \mu \mathrm{g} / \mathrm{kg}$ after the last postcontrol period $(165 \mathrm{~min})$ was completed. Heart rate failed to rise significantly with injection of isoproterenol after the administration of propranolol (a change of $0 \pm 3$ beats $/ \mathrm{min}$ ) and was significantly reduced $(P<0.0001)$ from the increase in heart rate of $135 \pm 18$ beats/min that had occurred with a comparable dose of isoproterenol during intact beta-adrenergic function.

Protocol III: combined acute hypoxemia and hypercapnic acidosis during vasopressin pressor inhibition with $d-\left(\mathrm{CH}_{2}\right)_{5} \mathrm{Tyr}(\mathrm{Me}) \mathrm{AVP}$ (n $=5$ ). To determine the role of vasopressin in changes observed during the combined stimulus, the vasopressin pressor antagonist [1-( $\beta$-mercapto- $\beta, \beta$-cyclopentamethylenepropionic acid), 2-(O-methyl)tyrosine]arginine-vasopressin [ $\left.d-\left(\mathrm{CH}_{2}\right)_{5} \mathrm{Tyr}(\mathrm{Me}) \mathrm{AVP}\right]$ in acetate/acetic acid vehicle at $10 \mu \mathrm{g} / \mathrm{kg}$ was injected as an intravenous bolus over 5 $\mathrm{min}$ in the intermediate period (40-45 min). The $d-\left(\mathrm{CH}_{2}\right)_{5} \mathrm{Tyr}(\mathrm{Me}) \mathrm{AVP}$ administered in the study was graciously supplied by Dr. Maurice Manning at the Medical College of Ohio (15). The administration of this pressor antagonist abolished the systemic pressor response to intravenous arginine vasopressin, $20 \mathrm{mU} / \mathrm{kg}$, to $-4 \pm 4 \mathrm{mmHg}$, which was significantly depressed $(P<0.01)$ compared with $19 \pm 4 \mathrm{mmHg}$ in the absence of the inhibitor in protocol I (Fig. 1).

To control for the effects of the vasopressin antagonist alone, the

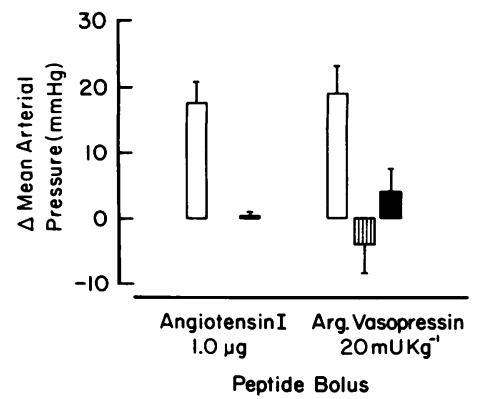

Figure 1. Administration of $d-\left(\mathrm{CH}_{2}\right)_{5} \mathrm{Tyr}(\mathrm{Me}) \mathrm{AVP}$ and [Sar ${ }^{1}$, Ala $^{8}$ ]-AII inhibited substantially the systemic pressor responses to intravenous boluses of arginine (Arg.) vasopressin and angiotensin I. Combined hypoxemia and hypercapnic acidosis with vehicles alone (ㅁ) $(n=6), d-$ $\left(\mathrm{CH}_{2}\right)_{5} \mathrm{Tyr}(\mathrm{Me}) \mathrm{AVP}$ (四) $(n=5)$, and [Sar', $\left.\mathrm{Ala}^{8}\right]$-AII plus $d-\left(\mathrm{CH}_{2}\right)_{5} \operatorname{Tyr}(\mathrm{Me}) \mathrm{AVP}$ (घ) $(n=6)$. protocol was precisely repeated with injection of $d-\left(\mathrm{CH}_{2}\right)_{5} \mathrm{Tyr}(\mathrm{Me}) \mathrm{AVP}$ in acetate/acetic acid vehicle at $10 \mu \mathrm{g} / \mathrm{kg}$ in the intermediate period (40$45 \mathrm{~min}$ ), except that the animals continued to breathe room air for from 45 to $85 \mathrm{~min}$. The administration of this vasopressin antagonist resulted in depression $(P<0.01)$ of the systemic pressor response to the intravenous bolus of arginine vasopressin, $20 \mathrm{mU} / \mathrm{kg}$, to $3 \pm 3 \mathrm{mmHg}$, compared with the systemic pressor response of $19 \pm 4 \mathrm{mmHg}$ in protocol I in the absence of the inhibitor.

Protocol IV: combined acute hypoxemia and hypercapnic acidosis during simultaneous vasopressin and angiotensin II inhibition $(n=6)$. Previous investigators observed that renin-angiotensin system activation compensates for the effects of vasopressin blockade in water-deprived rats and that the fall in systemic arterial pressure with vasopressin blockade is accentuated when combined with angiotensin II blockade (16). To prevent angiotensin II or vasopressin from masking the effects of inhibition of the alternate peptide, the angiotensin II and vasopressin inhibitors were administered simultaneously during combined hypoxemia and hypercapnic acidosis. The infusion of 1-sarcosine, 8-alanine angiotensin II ([Sar $\left.\left.{ }^{1}, \mathrm{Ala}^{8}\right]-\mathrm{AII}\right)$ in D5W at $2 \mu \mathrm{g} / \mathrm{kg}$ per min was begun at the onset of the intermediate period and continued through both combined stimulus periods (40-85 $\mathrm{min})$. The intravenous bolus of $d$ $\left(\mathrm{CH}_{2}\right)_{5} \mathrm{Tyr}(\mathrm{Me}) \mathrm{AVP}$ of $10 \mu \mathrm{g} / \mathrm{kg}$ in the acetate/acetic acid vehicle was administered in the intermediate period ( $40-45 \mathrm{~min})$, in a way identical to that in protocol III. The infusion of $\left[\mathrm{Sar}^{1}, \mathrm{Ala}^{8}\right]$-AII resulted in depression $(P<0.01)$ of the systemic pressor response to intravenous angiotensin I, $1,000 \mathrm{ng}$, to $0.2 \pm 1 \mathrm{mmHg}$, compared with $18 \pm 3 \mathrm{mmHg}$ in the absence of the inhibitor in protocol I (Fig. 1). The administration of $d$ $\left(\mathrm{CH}_{2}\right)_{5}$ Tyr(Me)AVP resulted in depression $(P<0.01)$ of the systemic pressor response to intravenous arginine vasopressin, $20 \mathrm{mU} / \mathrm{kg}$, to $4 \pm 3$ $\mathrm{mmHg}$, compared with $19 \pm 4 \mathrm{mmHg}$ in the absence of the inhibitor in protocol I (Fig. 1).

To determine if the combination of the angiotensin and vasopressin antagonists had nonspecific effects on systemic hemodynamic function, the protocol was precisely repeated, except that the animals breathed room air throughout the protocol $(n=5)$. The infusion of [Sar $\left.{ }^{1}, \mathrm{Ala}^{8}\right]-$ AII at $2 \mu \mathrm{g} / \mathrm{kg}$ per min for from 40 to $85 \mathrm{~min}$, and the injection of $d$ $\left(\mathrm{CH}_{2}\right)_{5} \mathrm{Tyr}(\mathrm{Me}) \mathrm{AVP}$ at $10 \mu \mathrm{g} / \mathrm{kg}$ in acetate/acetic acid vehicle from 40 to $45 \mathrm{~min}$ were identical. The systemic pressor response to intravenous angiotensin $\mathrm{I}, 1,000 \mathrm{ng}$, was reduced $(P<0.01)$ to $0 \pm 4 \mathrm{mmHg}$, compared with $18 \pm 3 \mathrm{mmHg}$ in the absence of angiotensin inhibition in protocol I. The systemic pressor response to intravenous arginine vasopressin, $20 \mathrm{mU} / \mathrm{kg}$, was reduced $(P<0.01)$ to $1 \pm 2 \mathrm{mmHg}$, compared with $19 \pm 4$ $\mathrm{mmHg}$ in the absence of vasopressin inhibition in protocol I.

Hemodynamic measurements and assays. Methods employed for hemodynamic measurements and assays have been described recently (5). Briefly, arterial pressure was measured from the carotid artery catheter and central venous pressure was measured from the external jugular venous catheter with vascular transducers (1280C; Hewlett-Packard Co., Instrument Products Group, Andover, MA) zeroed $5 \mathrm{~cm}$ dorsal to the sternum. Arterial pressure was measured at 2, 4, 6, 14, 16, and $18 \mathrm{~min}$ in each 20-min period. The measurements were averaged for two 20min periods to obtain single values for control, combined blood-gas derangement, and postcontrol periods. In addition, changes in arterial pressure were assessed every $10 \mathrm{~min}$ in these periods by averaging early $(2,4$, and $6 \mathrm{~min})$ and late $(14,16$, and $18 \mathrm{~min})$ measurements in each 20-min period. Cardiac output was calculated by the Stewart-Hamilton technique (17) from duplicate indicator-dilution dye curves generated by central venous injection of indocyanine green dye at the midpoint of each 20 -min period, with sampling of arterial blood by a cuvette densitometer (103IR; Gilford Instrument Laboratories, Inc., Oberlin, 
$\mathrm{OH}$ ) and a withdrawal pump (Harvard Apparatus Co., Inc., South Natick, MA). Total peripheral resistance was calculated by dividing mean arterial pressure by cardiac output. Systemic vascular resistance was calculated by subtracting central venous pressure from mean arterial pressure, and dividing by cardiac output. Resistance units were converted from millimeters of mercury per milliliter per second to dynes - seconds per centimeter $^{-5}$ by multiplying by 1,332 .

Blood samples were collected at the midpoint of each 20-min urine collection period. Specimens for plasma renin activity, and vasopressin and catecholamine concentrations were collected in EDTA, centrifuged at $4^{\circ} \mathrm{C}$, and stored at $-80^{\circ} \mathrm{C}$. Plasma renin activity $(18)$ and vasopressin concentrations (19) were measured by previously described radioimmunoassay techniques. The radioimmunoassay for vasopressin measures the vasopressin inhibitor $d-\left(\mathrm{CH}_{2}\right)_{5} \mathrm{Tyr}(\mathrm{Me}) \mathrm{AVP}$ as well as endogenous arginine vasopressin. Therefore, plasma vasopressin concentrations are not reported for protocols in which the vasopressin antagonist was administered.

Plasma epinephrine, norepinephrine, and dopamine concentrations were measured on $1.0-\mathrm{ml}$ specimens by high performance liquid chromatography with electrochemical detection by the method of Kissinger et al. (20). This technique has been validated previously by the radioenzymatic method (21). The characteristics of the technique at the University of Virginia are intraassay variability of $5 \%$ and interassay variability of $15 \%$ for norepinephrine, epinephrine, and dopamine determinations. Detection limits are $25 \mathrm{pg} / \mathrm{ml}$ for norepinephrine and epinephrine and $50 \mathrm{pg} / \mathrm{ml}$ for dopamine.

Arterial blood gases were collected anaerobically and analyzed with appropriate electrodes (model 113; Instrumentation Laboratory, Inc., Lexington, MA).

Data analysis. Data were analyzed by one- and two-way analysis of variance (22). If a significant $(P<0.05)$ treatment effect was identified for a variable in each protocol, multiple comparisons were performed by Duncan's multiple range test (22). Analysis of multiple measurements for mean arterial pressure and total peripheral resistance in each protocol (Figs. 4 and 5) were performed on data from control and combined blood-gas derangement periods by one-way analysis of variance. Responses between protocols were evaluated by comparing measurements during comparable periods by means of one-way analysis of variance. Unless noted, all group comparisons were considered insignificant $(P$ $\geq 0.05$ ). In the text, tables, and figures, variables are expressed as the mean \pm SE.

\section{Results}

Alterations in arterial blood gases. The induction of the combined blood-gas derangement resulted in comparable hypoxemia and hypercapnic acidosis during vehicles alone, beta-adrenergic blockade, and vasopressin and angiotensin II inhibition (Fig. 2). The hyperpneic response was comparable between protocols, and data were pooled. Minute ventilation increased $(P<0.01)$ from a control value of $5.1 \pm 1.0$ to $51.7 \pm 3.6$ liters $/ \mathrm{min}$ during combined hypoxemia and hypercapnic acidosis, and it decreased reversibly $(P<0.01)$ to $5.2 \pm 0.7$ liters $/ \mathrm{min}$ in the postcontrol period.

Effects of combined hypoxemia and hypercapnic acidosis with vehicles alone. Mean arterial pressure increased from control of $118 \pm 5$ to $139 \pm 5 \mathrm{mmHg}$ during the combined blood-gas derangement with vehicles alone and fell reversibly to $113 \pm 5$ $\mathrm{mmHg}$ during the postcontrol period (Fig. 3). This systemic

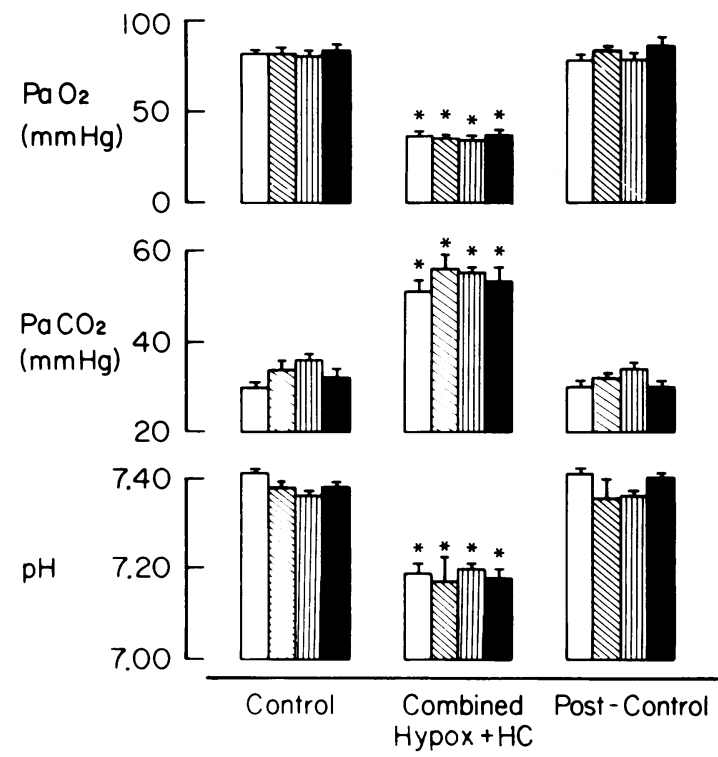

Figure 2. The severities of hypoxemia (top), hypercapnia (middle), and acidosis (bottom) were comparable during vehicle alone $(\square)(n$ $=6)$ and with administration of $d, l$-propranolol, (⿴囗十) $(n=5), d$ $\left(\mathrm{CH}_{2}\right)_{5} \operatorname{Tyr}(\mathrm{Me}) \mathrm{AVP}(\mathrm{m})(n=5)$ and combined vasopressin and angiotensin II inhibition $(\bullet)(n=6)$. Combined hypoxemia and hypercapnia acidosis, Hypox + HC. *Comparison with protocol control pe$\operatorname{riod} P<0.01$.

pressor response appeared to be related to increased cardiac output, since total peripheral resistance decreased during combined hypoxemia and hypercapnic acidosis with vehicles alone

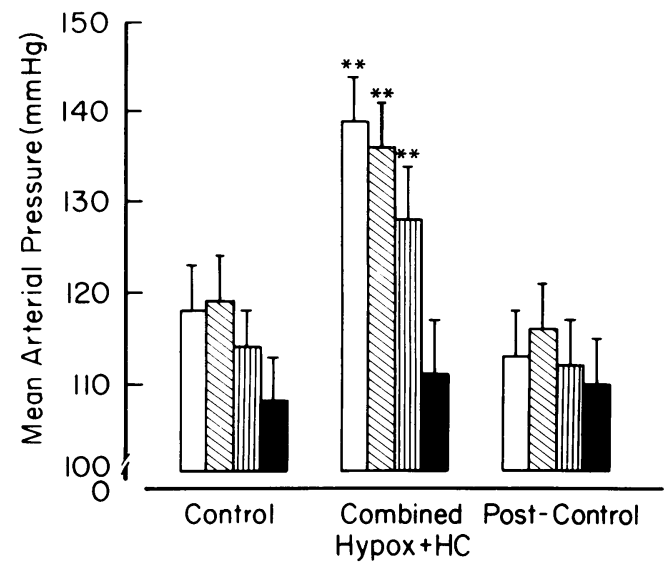

Figure 3. The increase in mean arterial pressure during combined hypoxemia and hypercapnic acidosis (Hypox $+\mathrm{HC}$ ) was unaltered during beta-adrenergic or vasopressin blockade, but was abrogated after administration of the vasopressin and angiotensin inhibitors together $(\square)(n=6)$. Combined Hypox $+\mathrm{HC}$ with vehicles alone (口) $(n=6)$, $d, l$-propranolol (ष) $(n=5)$, and $d-\left(\mathrm{CH}_{2}\right)_{5} \operatorname{Tyr}(\mathrm{Me}) \mathrm{AVP}$ (m) $(n=5)$. ${ }^{* *} P<0.01$, comparison with protocol control period. 
(Table I). In addition, systemic vascular resistance fell $(P$ $<0.01$ ) from a control value of $4,086 \pm 400$ to $2,514 \pm 135$ dynes $\cdot \mathrm{sec} \cdot \mathrm{cm}^{-5}$ during the combined blood-gas derangement and increased $(P<0.05)$ reversibly to $3,279 \pm 224$ dynes $\cdot \mathrm{sec} \cdot \mathrm{cm}^{-5}$ in the postcontrol period. Stroke volume was unchanged, whereas an increase in heart rate was observed during the combined blood gas derangement with vehicles alone (Table I).

Effects of combined hypoxemia and hypercapnic acidosis during beta-adrenergic blockade. Mean arterial pressure increased from a control value of $119 \pm 5$ to $136 \pm 5 \mathrm{mmHg}$ during combined hypoxemia and hypercapnic acidosis and beta-adrenergic blockade, and fell reversibly to $116 \pm 5 \mathrm{mmHg}$ in the postcontrol period (Fig. 3). This systemic pressor response was comparable to the increase in mean arterial pressure observed during the combined blood-gas derangement with vehicles alone (Table II). In addition, chronological analysis of mean arterial pressure revealed that the systemic pressor response during the combined blood-gas derangement with propranolol in protocol II was identical to combined hypoxemia and hypercapnic aci- dosis with vehicles alone in protocol I (Fig. 4). Cardiac output increased mildly during the combined blood-gas derangement with beta-adrenergic blockade (Table I), but the rise in cardiac output was significantly less than during combined hypoxemia and hypercapnic acidosis with vehicles alone (Table II). In addition, total peripheral resistance failed to decrease during the combined blood-gas derangement with propranolol (Table I). An inspection of early and late changes in total peripheral resistance revealed responses during the combined blood-gas derangements identical during beta-adrenergic blockade and vehicles alone (Fig. 5). Systemic vascular resistance was also unchanged from a control of $2,979 \pm 381$ to $2,496 \pm 194$ dynes $\cdot \mathrm{sec} \cdot \mathrm{cm}^{-5}$ during the combined blood-gas derangement with propranolol. Heart rate increased during combined hypoxemia and hypercapnic acidosis with beta-adrenergic blockade (Table I). Stroke volume fell in four of the five animals but was statistically unchanged compared with the control (Table I). However, the change in stroke volume from control to the combined blood-gas derangement period with propranolol was significantly different from the increase observed during the com-

Table I. Systemic Hemodynamic Function during Combined Hypoxemia and Hypercapnic Acidosis with Vasopressin, Angiotensin, or Beta-adrenergic Blockade

\begin{tabular}{|c|c|c|c|}
\hline Protocols & $\begin{array}{l}\text { Control } \\
(0-40 \mathrm{~min})\end{array}$ & $\begin{array}{l}\text { Combined Hypox } \\
\text { and } \mathrm{HC} \\
(45-85 \mathrm{~min})\end{array}$ & $\begin{array}{l}\text { Postcontrol } \\
(125-165 \mathrm{~min})\end{array}$ \\
\hline \multicolumn{4}{|c|}{ I. Combined Hypox and HC + vehicle $(n=6)$} \\
\hline $\mathrm{CO}($ liters/min $)$ & $2.4 \pm 0.3$ & $4.4 \pm 0.3^{*}$ & $2.9 \pm 0.2 \ddagger$ \\
\hline TPR $\left(\right.$ dynes $\left.\cdot \mathrm{s} \cdot \mathrm{cm}^{-5}\right)$ & $4,175 \pm 414$ & $2,554 \pm 137^{*}$ & $3,342 \pm 218$ \\
\hline $\mathrm{HR}($ beats/min) & $85 \pm 12$ & $128 \pm 5^{*}$ & $91 \pm 11$ \\
\hline $\mathrm{SV}(m l)$ & $30 \pm 4$ & $34 \pm 2$ & $33 \pm 4$ \\
\hline \multicolumn{4}{|c|}{ II. Combined Hypox and HC $+d, l$-propranolol $(n=5)$} \\
\hline $\mathrm{CO}$ (liters/min) & $3.3 \pm 0.4$ & $4.1 \pm 0.2 \ddagger$ & $2.8 \pm 0.1$ \\
\hline TPR (dynes $\left.\cdot \mathrm{s} \cdot \mathrm{cm}^{-5}\right)$ & $3,001 \pm 309$ & $2,695 \pm 189$ & $3,473 \pm 117$ \\
\hline HR (beats/min) & $90 \pm 11$ & $122 \pm 4 \ddagger$ & $76 \pm 10$ \\
\hline $\mathrm{SV}(m l)$ & $39 \pm 6$ & $34 \pm 2$ & $39 \pm 4$ \\
\hline \multicolumn{4}{|c|}{ III. Combined Hypox and $\mathrm{HC}+d-\left(\mathrm{CH}_{2}\right)_{5} \mathrm{Tyr}(\mathrm{Me}) \mathrm{AVP}(n=5)$} \\
\hline $\mathrm{CO}($ liters $/ \mathrm{min})$ & $3.2 \pm 0.4$ & $6.0 \pm 0.4^{*}$ & $4.0 \pm 0.5$ \\
\hline TPR (dynes $\left.\cdot \mathrm{s} \cdot \mathrm{cm}^{-5}\right)$ & $3,076 \pm 462$ & $1,759 \pm 142^{*}$ & $2,467 \pm 507$ \\
\hline HR (beats/min) & $83 \pm 8$ & $139 \pm 4^{*}$ & $101 \pm 10$ \\
\hline $\mathrm{SV}(m l)$ & $39 \pm 4$ & $43 \pm 3$ & $41 \pm 6$ \\
\hline \multicolumn{4}{|c|}{$\begin{array}{c}\text { IV. Combined Hypox and HC }+\left[\mathrm{Sar}^{1}, \mathrm{Ala}^{8}\right] \text {-AII } \\
+d-\left(\mathrm{CH}_{2}\right)_{5} \text { Tyr(Me)AVP }(n=6)\end{array}$} \\
\hline $\mathrm{CO}($ liters $/ \mathrm{min})$ & $2.7 \pm 0.4$ & $5.4 \pm 0.3^{*}$ & $3.9 \pm 0.3^{*}$ \\
\hline TPR (dynes $\left.\cdot \mathrm{s} \cdot \mathrm{cm}^{-5}\right)$ & $3,750 \pm 723$ & $1,692 \pm 170^{*}$ & $2,329 \pm 223^{*}$ \\
\hline HR (beats/min) & $88 \pm 10$ & $140 \pm 6^{*}$ & $104 \pm 7$ \\
\hline SV $(m l)$ & $28 \pm 4$ & $39 \pm 3 \ddagger$ & $39 \pm 4$ \\
\hline
\end{tabular}

Combined Hypox and HC, combined hypoxemia and hypercapnic acidosis; CO, cardiac output; TPR, total peripheral resistance; HR, heart rate; SV, stroke volume. * Denotes significant difference from protocol control value, $P<0.01$. $\ddagger$ Denotes significant difference from protocol control value, $P<0.05$. 
Table II. Change in Systemic Hemodynamic Function during Combined Hypoxemia and Hypercapnic Acidosis with Vasopressin, Angiotensin, or Beta-adrenergic Blockade

\begin{tabular}{|c|c|c|c|c|c|}
\hline Combined Hypox and HC plus & $\triangle$ MAP & $\Delta \mathrm{CO}$ & $\triangle T P R$ & $\Delta \mathrm{HR}$ & $\Delta \mathbf{S V}$ \\
\hline & $\mathrm{mmHg}$ & liters/min & dynes $\cdot \mathrm{s} \cdot \mathrm{cm}^{-s}$ & beats/min & $m l$ \\
\hline I. Vehicles alone $(n=6)$ & $21 \pm 3^{*}$ & $2.0 \pm 0.3^{*}$ & $-1,622 \pm 393^{*}$ & $44 \pm 11^{*}$ & $5 \pm 3$ \\
\hline II. $d, l$-propranolol $(n=5)$ & $17 \pm 1^{*}$ & $0.8 \pm 0.3 \ddagger \S$ & $-316 \pm 278$ & $33 \pm 8 \S$ & $-5 \pm 5$ \\
\hline III. $d-\left(\mathrm{CH}_{2}\right) \operatorname{Tyr}(\mathrm{Me}) \mathrm{AVP}(n=5)$ & $14 \pm 3^{*}$ & $2.8 \pm 0.5^{*}$ & $-1,318 \pm 378^{*}$ & $56 \pm 7^{*}$ & $4 \pm 4$ \\
\hline IV. $d-\left(\mathrm{CH}_{2}\right)_{5} \mathrm{Tyr}(\mathrm{Me}) \mathrm{AVP}$ and & & & & & \\
\hline$\left[\mathrm{Sar}^{1}, \mathrm{Ala}^{8}\right]$-AII $(n=6)$ & $3 \pm 4 \ddagger$ & $2.7 \pm 0.3^{*}$ & $-2,059 \pm 633^{*}$ & $52 \pm 8^{*}$ & $11 \pm 2 \S$ \\
\hline
\end{tabular}

Combined Hypox and HC, combined hypoxemia and hypercapnic acidosis; MAP, mean arterial pressure; CO, cardiac output; TPR, total peripheral resistance; $\mathrm{HR}$, heart rate; $\mathrm{SV}$, stroke volume. $\triangle$ Change in variable from control to combined blood-gas derangement. ${ }^{*}$ Denotes significant change in variable from control to combined blood gas derangement period, $P<0.01$. $\ddagger$ Denotes significant difference in the $\Delta$ for any variable in a protocol from the $\Delta$ during the combined blood gas derangement with vehicles alone, $P<0.05$. $\S$ Denotes significant change in variable from control to combined blood-gas derangement period, $P<0.05$.

bined blood-gas derangement with simultaneous vasopressin pressor and angiotensin II blockade in protocol IV (Table II).

Combined hypoxemia and hypercapnic acidosis with $d$ $\left(\mathrm{CH}_{2}\right)_{5} \mathrm{Tyr}(\mathrm{Me}) \mathrm{AVP}$. Mean arterial pressure increased from a control value of $114 \pm 4$ to $128 \pm 6 \mathrm{mmHg}$ during combined hypoxemia and hypercapnic acidosis with vasopressin antagonism using $d-\left(\mathrm{CH}_{2}\right)_{5} \mathrm{Tyr}(\mathrm{Me}) \mathrm{AVP}$ in protocol III, and it decreased reversibly $(P<0.01)$ to $112 \pm 5 \mathrm{mmHg}$ in the postcontrol period

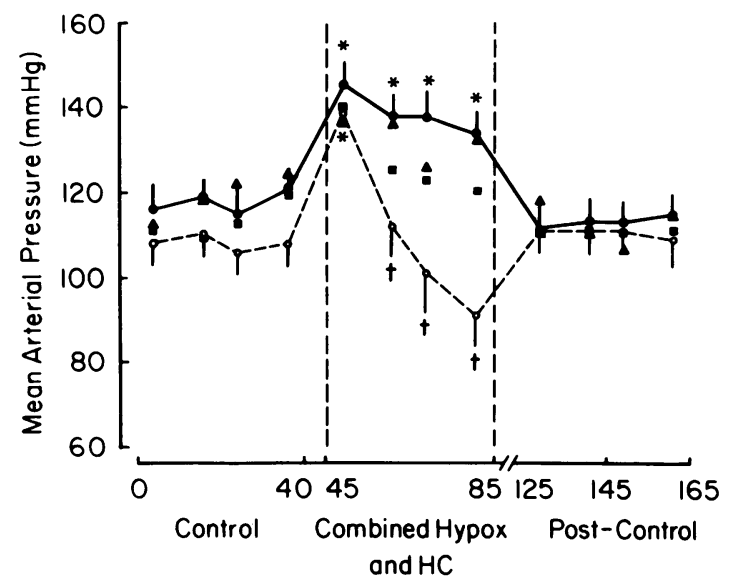

Figure 4. Mean arterial pressure fell progressively during the latter 30 min of combined hypoxemia and hypercapnic acidosis (Hypox and HC) with vasopressin pressor and angiotensin II blockade (open circles, broken line) $(n=6)$, and was diminished compared with the combined blood-gas derangement with vehicles alone (solid circles, solid line) $(n=6)$. Measurements are also shown for combined hypoxemia and hypercapnic acidosis with $d, l$-propranolol (closed triangles) $(n=5)$, the combined blood-gas derangement with d- $\left(\mathrm{CH}_{2}\right)_{s} \mathrm{Tyr}(\mathrm{Me}) \mathrm{AVP}$ (closed squares) $(n=5)$. "Comparison with last measurement of mean arterial pressure in the control period; $P$ $<0.05$. †Comparison with the comparable period during the combined blood-gas derangement with vehicles alone; $P<0.05$.
(Fig. 3). This systemic pressor response was comparable (Table II) to the combined blood-gas derangement with vehicles alone in protocol I. In addition, a comparison of early and late measurements of mean arterial pressure revealed comparable re-

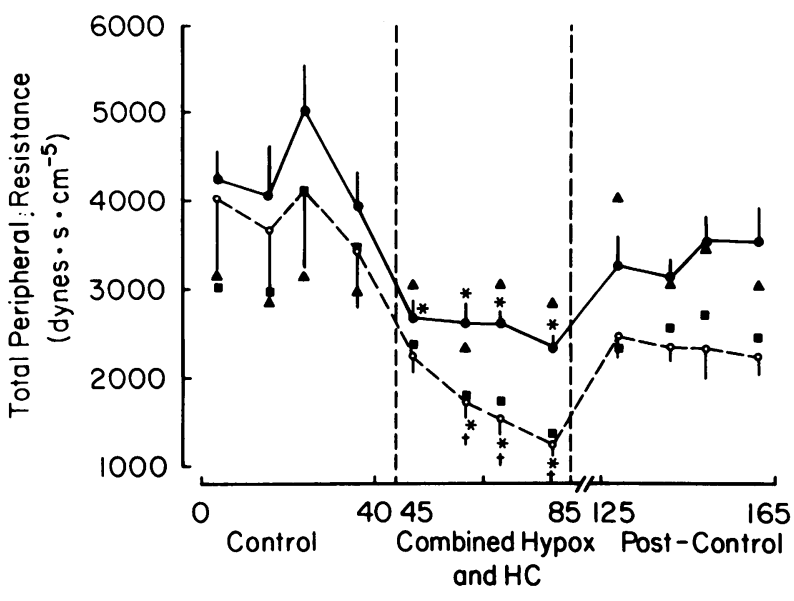

Figure 5. Total peripheral resistance decreased progressively during the last $30 \mathrm{~min}$ of the combined hypoxemia and hypercapnic acidosis (Hypox $+\mathrm{HC}$ ) with vasopressin pressor and angiotensin II blockade (open circles, broken line) $(n=6)$, and was diminished compared with the combined blood-gas derangement with vehicles alone (closed circles, solid line) ( $n=6)$. Total peripheral resistance was also diminished during the combined blood-gas derangement with vasopressin pressor blockade alone (closed squares) compared with combined hypoxemia and hypercapnic acidosis with vehicles alone. The total peripheral resistance response during the combined blood gas derangement with $d, l$-propranolol (closed triangles) resembled the response during combined hypoxemia and hypercapnic acidosis with vehicles alone. "Comparison with last measurements of total peripheral resistance in the control period. $P<0.05$. †Comparison with the comparable period during the combined stimulus with vehicles alone. $P<0.05$. 
sponses between the combined blood-gas derangement with vehicles alone in protocol I and with $d-\left(\mathrm{CH}_{2}\right)_{5} \mathrm{Tyr}(\mathrm{Me}) \mathrm{AVP}$ in protocol III (Fig. 4). Cardiac output increased and total peripheral resistance decreased during combined hypoxemia and hypercapnic acidosis with $d-\left(\mathrm{CH}_{2}\right)_{5} \mathrm{Tyr}(\mathrm{Me}) \mathrm{AVP}$ (Table I); the overall changes in these variables were comparable to the combined blood-gas derangement with vehicles alone in protocol I (Table II). Systemic vascular resistance also decreased $(P<0.01)$ from a control value of $3,026 \pm 434$ to $1,743 \pm 128$ dynes $\cdot \mathrm{sec} \cdot$ $\mathrm{cm}^{-5}$ during the combined blood-gas derangement with $d$ $\left(\mathrm{CH}_{2}\right)_{5} \mathrm{Tyr}(\mathrm{Me}) \mathrm{AVP}$. However, compared with the combined blood-gas derangement with vehicles alone in protocol I or with beta-adrenergic blockade in protocol II, total peripheral resistance was diminished during the last $30 \mathrm{~min}$ of combined hypoxemia and hypercapnic acidosis with $d-\left(\mathrm{CH}_{2}\right)_{5} \mathrm{Tyr}(\mathrm{Me}) \mathrm{AVP}$ in protocol III (Fig. 5). Heart rate increased reversibly during the combined blood gas derangement with vasopressin blockade (Table I), but stroke volume was unchanged. The change in heart rate and stroke volume was comparable to combined hypoxemia and hypercapnic acidosis with vehicles alone in protocol I (Table II).

Effects of d-(CH$)_{5}$ Tyr $(\mathrm{Me}) \mathrm{AVP}$ alone. The $\mathrm{PaO}_{2}$ and $\mathrm{PaCO}_{2}$ were unchanged from control values of $82 \pm 2$ and $33 \pm 1 \mathrm{mmHg}$, respectively, with the administration of $d-\left(\mathrm{CH}_{2}\right)_{5} \mathrm{Tyr}(\mathrm{Me}) \mathrm{AVP}$. In addition, arterial blood $\mathrm{pH}$ and minute ventilation were unchanged from control values of $7.33 \pm 0.01$ and $4.6 \pm 0.9$ liters/min.

Mean arterial pressure and heart rate (Table III) were both unchanged with the administration of $d-\left(\mathrm{CH}_{2}\right)_{5} \mathrm{Tyr}(\mathrm{Me}) \mathrm{AVP}$ during normal gas exchange. Although both cardiac output and

Table III. Systemic Hemodynamic Function with Vasopressin and Angiotensin Blockade during Normoxemia and Normocapnia

\begin{tabular}{|c|c|c|c|}
\hline Protocols & $\begin{array}{l}\text { Control } \\
(0-40 \mathrm{~min})\end{array}$ & $\begin{array}{l}\text { Infusion of } \\
\text { inhibitors } \\
(45-85 \mathrm{~min})\end{array}$ & $\begin{array}{l}\text { Postcontrol } \\
(125-165 \mathrm{~min})\end{array}$ \\
\hline \multicolumn{4}{|l|}{$\begin{array}{c}\text { III. } d-\left(\mathrm{CH}_{2}\right)_{5} \mathrm{Tyr}(\mathrm{Me}) \mathrm{AVP} \\
\text { alone }(n=4)\end{array}$} \\
\hline MAP $(m m H g)$ & $113 \pm 5$ & $108 \pm 7$ & $109 \pm 1$ \\
\hline CO (liters/min) & $2.7 \pm 0.3$ & $2.8 \pm 0.4$ & $3.4 \pm 0.4^{*}$ \\
\hline TPR $\left(\right.$ dynes $\left.\cdot \mathrm{s} \cdot \mathrm{cm}^{-5}\right)$ & $3,614 \pm 646$ & $3,291 \pm 559$ & $2,724 \pm 388 \ddagger$ \\
\hline HR (beats/min) & $85 \pm 6$ & $97 \pm 12$ & $110 \pm 17$ \\
\hline SV $(m l)$ & $32 \pm 2$ & $29 \pm 2$ & $31 \pm 1$ \\
\hline \multicolumn{4}{|l|}{$\begin{array}{l}\left.\text { IV. [Sar }{ }^{1}, \mathrm{Ala}^{8}\right] \text {-AII and } \\
\begin{array}{l}d-\left(\mathrm{CH}_{2}\right)_{s} \mathrm{Tyr}(\mathrm{Me}) \mathrm{AVP} \\
(n=5)\end{array}\end{array}$} \\
\hline MAP $(m m H g)$ & $119 \pm 6$ & $117 \pm 5$ & $118 \pm 4$ \\
\hline CO (liters/min) & $2.6 \pm 0.2$ & $2.6 \pm 0.2$ & $3.4 \pm 0.3$ \\
\hline TPR $\left(\right.$ dynes $\left.\cdot s \cdot \mathrm{cm}^{-5}\right)$ & $3,778 \pm 240$ & $3,782 \pm 356$ & $2,833 \pm 273 \ddagger$ \\
\hline HR (beats/min) & $82 \pm 6$ & $80 \pm 3$ & $98 \pm 6 \ddagger$ \\
\hline SV $(m l)$ & $32 \pm 2$ & $32 \pm 2$ & $36 \pm 4$ \\
\hline
\end{tabular}

MAP, mean arterial pressure; CO, cardiac output; TPR, total peripheral resistance; HR, heart rate; SV, stroke volume.

* Denotes significant difference from protocol control value, $P<0.01$.

‡ Denotes significant difference from protocol control value, $P<0.05$. total peripheral resistance were unchanged in the 40-min period after the injection of $d-\left(\mathrm{CH}_{2}\right)_{5} \mathrm{Tyr}(\mathrm{Me}) \mathrm{AVP}$, cardiac output increased and total peripheral resistance decreased in the postcontrol period (Table III). In addition, stroke volume was unchanged with the administration of the vasopressin pressor antagonist (Table III).

Combined hypoxemia and hypercapnic acidosis with simultaneous vasopressin and angiotensin II blockade. Mean arterial pressure was comparable during the control periods between combined blood-gas derangement protocols with vehicles alone, beta-adrenergic blockade, and vasopressin and angiotensin II inhibition (Fig. 3). In contrast to all other combined bloodgas derangement protocols, the average systemic pressor response during the combined blood-gas derangement with simultaneous vasopressin and angiotensin II blockade was abolished. This was reflected in unchanged mean arterial pressure from a control value of $108 \pm 5$ to $111 \pm 6 \mathrm{mmHg}$ during combined hypoxemia and hypercapnic acidosis with both inhibitors (Fig. 3). Moreover, the change in mean arterial pressure from control to the combined blood-gas derangement periods during simultaneous vasopressin and angiotensin II blockade was significantly different $(P<0.05)$ from the response during the combined blood-gas derangement with vehicles alone in protocol $I$, in contrast to responses during the combined blood-gas derangement with beta-adrenergic blockade in protocol II or vasopressin blockade alone in protocol III (Table II). Chronological analysis of the systemic pressor response revealed that the early rise in mean arterial pressure in the first $10 \mathrm{~min}$ of the combined blood-gas derangement with vehicles alone was present during combined hypoxemia and hypercapnic acidosis with simultaneous vasopressin and angiotensin II inhibition in protocol IV (Fig. 4). However, mean arterial pressure subsequently fell progressively during the ensuing $30 \mathrm{~min}$ of the combined blood-gas derangement with both inhibitors and was significantly diminished from the combined blood-gas derangement with vehicles alone (Fig. 4).

Cardiac output increased and total peripheral resistance fell during the combined blood-gas derangement with simultaneous administration of both inhibitors (Table I). In addition, cardiac output and total peripheral resistance remained elevated and decreased, respectively, in the postcontrol period, compared with control. The overall changes in cardiac output and total peripheral resistance were comparable to combined hypoxemia and hypercapnic acidosis with vehicles alone in protocol I (Table II). Systemic vascular resistance also decreased $(P<0.01)$ from a control value of $3,715 \pm 706$ to $1,655 \pm 164$ dynes $\cdot \mathrm{sec} \cdot \mathrm{cm}^{-5}$ during the combined blood-gas derangement with both inhibitors. Total peripheral resistance fell in parallel with mean arterial pressure during the latter $30 \mathrm{~min}$ of combined hypoxemia and hypercapnic acidosis with angiotensin II and vasopressin pressor inhibition, and was diminished compared with the combined blood-gas derangement with vehicles alone in protocol I or with beta-adrenergic inhibition in protocol II (Fig. 5). Both heart rate and stroke volume increased during the combined blood- 
gas derangement with both inhibitors (Table I). However, the change in heart rate and stroke volume during the combined blood gas derangement with vasopressin and angiotensin II inhibition was comparable to combined hypoxemia and hypercapnic acidosis with vehicles alone in protocol I (Table II).

Effects of d-( $\left(\mathrm{CH}_{2}\right)_{5} \mathrm{Ty}$ r(Me)AVP and [Sar $\left.{ }^{l}, \mathrm{Ala}{ }^{8}\right]-$ AII alone. Both $\mathrm{PaO}_{2}$ and $\mathrm{PaCO}_{2}$ were unchanged from control values of $100 \pm 7$ and $29 \pm 8 \mathrm{mmHg}$, respectively, with the administration of vasopressin pressor and angiotensin II antagonists while the animals breathed room air. In addition, arterial blood $\mathrm{pH}$ and minute ventilation were unchanged from control of $7.37 \pm 0.01$ and $4.2 \pm 0.7$ liters $/ \mathrm{min}$.

Mean arterial pressure, cardiac output, total peripheral resistance, and heart rate (Table III) were unchanged with combined administration of $d-\left(\mathrm{CH}_{2}\right)_{5} \mathrm{Tyr}(\mathrm{Me}) \mathrm{AVP}$ and [ $\left.\mathrm{Sar}^{1}, \mathrm{Ala}^{8}\right]-$ AII, but total peripheral resistance fell and heart rate increased in the postcontrol period. Stroke volume was unchanged with administration of the vasopressin pressor and angiotensin II antagonists.

Changes in plasma renin activity and circulating vasopressin and catecholamines. Plasma renin activity increased comparably during the combined blood gas derangement with vehicles alone, $d, l$-propranolol, $d$ - $\left(\mathrm{CH}_{2}\right)_{5} \mathrm{Tyr}(\mathrm{Me}) \mathrm{AVP}$, and simultaneous vasopressin pressor and angiotensin II blockade (Fig. 6). In addition, the rise in plasma renin activity from control to combined hypoxemia and hypercapnic acidosis with beta-adrenergic inhibition and vasopressin pressor and angiotensin II blockade was comparable to the combined blood-gas derangement with vehicles alone.

Plasma arginine vasopressin concentrations increased $(P$ $<0.01$ ) substantially from a control value of $1.1 \pm 0.4$ to $21.5 \pm 6.6$

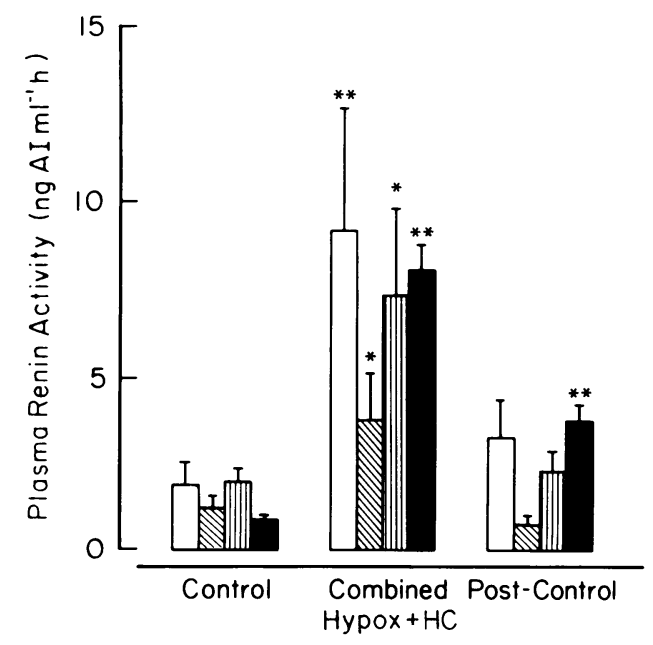

Figure 6. The rise in plasma renin activity during combined hypoxemia and hypercapnic acidosis (Hypox $+\mathrm{HC}$ ) with d,l-propranolol $(\square)(n=5)$, or vasopressin and angiotensin II blockade $(\square)(n=6)$ was comparable to the combined blood-gas derangement with vehicles alone $(\square)(n=6) . \mathrm{m}$, vasopressin pressor blockade alone. ${ }^{*} P$ $<0.05,{ }^{* *} \mathrm{P}<0.01$; both comparison with protocol control period. $\mathrm{pg} / \mathrm{ml}$ during combined hypoxemia and hypercapnic acidosis with vehicles alone and were $1.7 \pm 0.6 \mathrm{pg} / \mathrm{ml}$ in the postcontrol period.

Circulating norepinephrine was unchanged during combined hypoxemia and hypercapnic acidosis with vehicles alone but increased profoundly during the combined blood-gas derangement with combined vasopressin pressor and angiotensin Il blockade (Table IV). Plasma norepinephrine concentrations were elevated comparably during the first and second 20 -min periods of the combined blood-gas derangement with vasopressin pressor and angiotensin II blockade in protocol IV. Moreover, the change in plasma norepinephrine concentrations from control to combined hypoxemia and hypercapnic acidosis with simultaneous vasopressin pressor and angiotensin II inhibition in protocol IV exceeded $(P<0.025)$ the response during the combined bloodgas derangement with vehicles alone in protocol I. Circulating epinephrine was unchanged during the combined blood gas derangement with vehicles alone (Table IV). Although plasma epinephrine concentrations increased in all six dogs during the combined blood-gas derangement with both inhibitors in protocol IV, the change was not statistically significant, probably because of a hyper-response in one dog. Plasma dopamine concentrations were unchanged during the combined blood-gas derangement with vehicles alone but increased during combined hypoxemia and hypercapnic acidosis with both inhibitors (Table IV).

\section{Discussion}

The present study demonstrates that vasopressin and angiotensin II are important contributors to the systemic pressor response

Table IV. Circulating Catecholamines during Combined Hypoxemia and Hypercapnic Acidosis with Vehicles Alone or Combined Vasopressin and Angiotensin II Inhibition

\begin{tabular}{|c|c|c|c|}
\hline Protocols & $\begin{array}{l}\text { Control } \\
(0-40 \mathrm{~min})\end{array}$ & $\begin{array}{l}\text { Combined } \\
\text { Hypox } \\
\text { and } \mathrm{HC} \\
(45-85 \mathrm{~min})\end{array}$ & $\begin{array}{l}\text { Postcontrol } \\
(125-165 \mathrm{~min})\end{array}$ \\
\hline \multicolumn{4}{|c|}{$\begin{array}{l}\text { Combined Hypox and } \mathrm{HC} \\
+ \text { vehicle }\end{array}$} \\
\hline $\operatorname{NE}(p g / m l)(n=6)$ & $82 \pm 28$ & $244 \pm 133$ & $55 \pm 12$ \\
\hline $\mathrm{E}(p g / m l)(n=6)$ & $106 \pm 22$ & $300 \pm 124$ & $122 \pm 42$ \\
\hline $\mathrm{DA}(p g / m l)(n=4)$ & $82 \pm 60$ & $30 \pm 14$ & $25 \pm 8$ \\
\hline \multicolumn{4}{|c|}{$\begin{array}{l}\text { Combined Hypox and HC } \\
+\left[\mathrm{Sar}^{1}, \mathrm{Ala}^{8}\right]-\mathrm{AII} \\
\quad+d-\left(\mathrm{CH}_{2}\right)_{5} \mathrm{Tyr}(\mathrm{Me}) \mathrm{AVP}\end{array}$} \\
\hline $\mathrm{NE}(p g / m l)(n=6)$ & $188 \pm 38$ & $1,719 \pm 452^{*}$ & $250 \pm 38$ \\
\hline $\mathrm{E}(p g / m l)(n=6)$ & $329 \pm 74$ & $1,317 \pm 643$ & $392 \pm 58$ \\
\hline $\mathrm{DA}(p g / m l)(n=5)$ & $64 \pm 17$ & $250 \pm 39^{*}$ & $131 \pm 23$ \\
\hline
\end{tabular}

Combined Hypox and HC, combined hypoxemia and hypercapnic acidosis; NE, plasma norepinephrine concentrations; E, plasma epinephrine concentrations; DA, plasma dopamine concentrations.

* Denotes significant difference from control, $P<0.01$. 
during combined hypoxemia and hypercapnic acidosis. This was reflected by a progressive fall in mean arterial pressure and total peripheral resistance during the combined blood-gas derangement with simultaneous vasopressin pressor and angiotensin II inhibition.

It is unlikely that the systemic pressor response during combined hypoxemia and hypercapnic acidosis depends solely upon increased cardiac output. The rise in mean arterial pressure during the combined blood-gas derangement in the face of decreased total peripheral resistance suggests a central role for increased cardiac output. However, a comparable rise in mean arterial pressure occurred during combined hypoxemia and hypercapnic acidosis with beta-adrenergic blockade, with a reduced rise in cardiac output and an unchanged total peripheral resistance. Moreover, mean arterial pressure was unchanged during the combined blood-gas derangement with simultaneous vasopressin pressor and angiotensin II inhibition when cardiac output was elevated and total peripheral resistance was further diminished. These data suggest that changes in both flow and resistance in the systemic circulation are important factors in the systemic pressor response during the combined blood-gas derangement. The increase in cardiac output during combined hypoxemia and hypercapnic acidosis appears to be mediated largely by the beta-adrenergic system. The concomitant fall in total peripheral resistance is probably the summation of the effects of multiple factors, including the beta-adrenergic system, vasopressin, and angiotensin II. Although the present study does not identify all the factors responsible for the control of total peripheral resistance during the combined blood-gas derangement, it is clear that vasopressin and angiotensin II are important contributors to the rise in mean arterial pressure by limiting the fall in total peripheral resistance so that the rise in cardiac output predominates.

Although recent studies have identified an important role for vasopressin during dehydration $(16,23)$ and nonhypotensive hemorrhage (24), the physiological significance of increased circulating vasopressin during acute hypoxemia and hypercapnic acidosis $(11,12,19)$ has not been evaluated.

The present study was undertaken to evaluate the role of vasopressin during combined hypoxemia and hypercapnic acidosis by the administration of $d-\left(\mathrm{CH}_{2}\right)_{5} \mathrm{Tyr}(\mathrm{Me}) \mathrm{AVP}$, a recently developed antagonist of the vasoconstrictive effects of arginine vasopressin (15). The efficacy of this antagonist in the present study is demonstrated by inhibition of the systemic pressor response to arginine vasopressin, confirming previous observations in anesthetized rats (15). Although total peripheral resistance was diminished compared with combined hypoxemia and hypercapnic acidosis with vehicles alone, the rise in mean arterial pressure was unaltered during the combined blood-gas derangement with vasopressin pressor antagonism alone, probably because of activation of the renin-angiotensin system. The absence of augmentation in plasma renin activity with vasopressin pressor antagonism contrasts with an accentuated rise in plasma renin activity in conscious dogs with administration of vasopressin pressor inhibitors during nonhypotensive hemorrhage (24) and water deprivation (23). The lack of enhancement in the rise in plasma renin activity during the combined blood-gas derangement with vasopressin pressor blockade may account for the pronounced fall in total peripheral resistance comparable to combined hypoxemia and hypercapnic acidosis with vasopressin pressor and angiotensin II inhibition. The reasons for the lack of augmentation in plasma renin activity with vasopressin pressor inhibition are unclear.

We have recently observed that angiotensin II inhibition alone also failed to alter the rise in mean arterial pressure and the decrease in total peripheral resistance during combined hypoxemia and hypercapnic acidosis in conscious dogs (5). However, inhibition of angiotensin II during the combined bloodgas derangement resulted in diminished renal hemodynamic function (5). Possible explanations for the failure of angiotensin II inhibition to abolish the systemic pressor response during combined hypoxemia and hypercapnic acidosis in these previous experiments include inadequate angiotensin II blockade, decreased systemic vascular responsiveness to angiotensin II, and enhanced vasopressin secretion. A high degree of angiotensin II blockade was observed in the previous study, as evidenced by the abolition of the systemic pressor response to intravenous angiotensin I. In addition, previous observations indicate that intrarenal infusion of [ $\left.\mathrm{Sar}^{1}, \mathrm{Ala}^{8}\right]$-AII at $2.5 \mu \mathrm{g} / \mathrm{kg}$ per min results in $>80 \%$ inhibition of the systemic pressor response to angiotensin I within the first $10 \mathrm{~min}$ (25). Thus, inadequate angiotensin inhibition in the previous study is unlikely. Decreased responsiveness to angiotensin I seems unlikely in view of the systemic pressor response to angiotensin I during the combined bloodgas derangement in the present study.

The findings of the present study are most consistent with the possibility that enhanced secretion of vasopressin offsets the effects of angiotensin II inhibition during the combined stimulus. This enhanced secretion of vasopressin with functional ablation of the renin-angiotensin system has been observed previously with hypotensive hemorrhage in anesthetized dogs (26). In support of this possibility, when angiotensin II and vasopressin blockade were imposed simultaneously during combined hypoxemia and hypercapnic acidosis in the present study, mean arterial pressure and total peripheral resistance fell progressively after the unaltered rise in mean arterial pressure in the first $10 \mathrm{~min}$.

Taken together, the present experiments clearly demonstrate important roles for angiotensin II and vasopressin in the systemic pressor response during combined hypoxemia and hypercapnic acidosis.

The interaction between angiotensin II and vasopressin in the present study is indicated by the independent ability of each system to support the rise in mean arterial pressure when either system is functionally inactivated. The existence of dual mechanisms involving angiotensin II and vasopressin for the maintenance of circulatory homeostasis has been described previously during water deprivation in the anesthetized rat (16) and after autonomic blockade in the anesthetized dog (27). However, other forms of vasopressin/angiotensin II interaction, such as 
angiotensin II-induced vasopressin release (28) and vasopressin inhibition of renin secretion (29), are not evident in the present observations.

The beta-adrenergic component of the sympathetic nervous system also plays an important role in the systemic pressor response during combined hypoxemia and hypercapnic acidosis, through increased cardiac output. In addition, an early rise in the first $10 \mathrm{~min}$ in mean arterial pressure occurred despite the simultaneous administration of vasopressin pressor and angiotensin II antagonists. No previous studies have evaluated the effects of inhibition of the sympathetic nervous system during combined hypoxemia and hypercapnic acidosis.

Beta-adrenergic blockade probably limited the increase in cardiac output during the combined blood-gas derangement through decreased stroke volume, since the tachycardic response was unaltered. Although stroke volume fell in four of five dogs from control to combined hypoxemia and hypercapnic acidosis with propranolol, the change was not significant. However, the fall in stroke volume from control to the combined blood-gas derangement with propranolol was significantly different from the increase in stroke volume during combined hypoxemia and hypercapnic acidosis with both inhibitors. The failure of betaadrenergic blockade to abolish the tachycardia during the combined blood-gas derangement indicates neither absence of involvement of the sympathetic nervous system nor inadequate blockade. In sympathectomized conscious dogs with 6-hydroxydopamine and adrenalectomy, Hammill and colleagues (30) observed tachycardia during acute hypoxemia, secondary to diminished parasympathetic tone. In intact animals, parasympathetic blockade alone with atropine failed to expunge the tachycardia of acute hypoxemia. However, when parasympathetic blockade was added to interruption of the sympathetic nervous system, the tachycardia of acute hypoxemia was abolished. Although the stimulus of hypoxemia alone in this previous study differs from the combined blood-gas derangement in the present study, the mechanism of tachycardia may be comparable.

Unchanged circulating catecholamines during combined hypoxemia and hypercapnic acidosis with vehicles alone does not exclude a role for the beta-adrenergic system on the rise in cardiac output and heart rate and decrease in total peripheral resistance in the present study. Changes in circulating catecholamines are a rough index of activation of the sympathetic nervous system and may incorrectly reflect the state of activation of the sympathetic nervous system, especially in neurally mediated events. We have previously observed increased circulating catecholamines in conscious dogs during combined hypoxemia and hypercapnic acidosis (8). However, the combined bloodgas derangement in which circulating catecholamines rose was always preceded by $80 \mathrm{~min}$ of either acute hypoxemia alone or acute hypercapnic acidosis alone. This difference in the present study may account for unchanged circulating catecholamines.

The sustained rise in circulating catecholamines during the second $20 \mathrm{~min}$ of the combined stimulus with parallel inhibition of angiotensin II and vasopressin is strong evidence against diminished activity of the sympathetic nervous system. Increased beta-adrenergic stimulation may have contributed to the progressive fall in total peripheral resistance in the latter $30 \mathrm{~min}$ of the combined blood-gas derangement with both inhibitors.

In summary, the present experiments demonstrate an important role for vasopressin and angiotensin II in the rise in mean arterial pressure during combined hypoxemia and hypercapnic acidosis in conscious dogs through maintenance of total peripheral resistance, so that the beta-adrenergically mediated increase in cardiac output predominates. When the actions of both hormones were inhibited, mean arterial pressure fell after an initial rise in the first $10 \mathrm{~min}$ of the combined bloodgas derangement. These studies suggest important physiological roles for vasopressin and angiotensin II in healthy human subjects and patients during hypoxemia and hypercapnic acidosis.

\section{Acknowledgments}

This work was supported by grants HL 28118-01, HL 22306, AM 26111, and AM 34408 from the National Institutes of Health, and by a grant from the American Heart Association, Virginia Affiliate.

\section{References}

1. Schneider, E. C., and D. Truesdell. 1921. A study of low oxygen effects during rebreathing. Am. J. Physiol. 55:223-257.

2. Dripps, R. D., and J. H. Comroe. 1947. The effect of the inhalation of high and low oxygen concentrations on respiration, pulse rate, ballistocardiogram and arterial oxygen saturation (oximeter) of normal individuals. Am. J. Physiol. 149:277-291.

3. Dripps, R. D., and J. H. Comroe. 1947. The respiratory and circulatory response of normal man to inhalation of 7.6 and 10.4 per cent $\mathrm{CO}_{2}$ with a comparison of the maximal ventilation produced by severe muscular exercise, inhalation of $\mathrm{CO}_{2}$ and maximal voluntary hyperventilation. Am. J. Physiol. 149:43-51.

4. Gellhorn, E. 1937. Circulatory studies on anoxemia in man with respect to posture and carbon dioxide. Ann. Intern. Med. 10:1267-1278.

5. Rose, C. E., D. P. Kimmel, R. L. Godine, D. L. Kaiser, and R. M. Carey. 1983. Synergistic effects of acute hypoxemia and hypercapnic acidosis in conscious dogs. Renal dysfunction and activation of the renin-angiotensin system. Circ. Res. 53:202-213.

6. Nahas, G. G., G. W. Mather, J. D. M. Wargo, and W. L. Adams. 1954. Influence of acute hypoxia on sympathectomized and adrenalectomized dogs. Am. J. Physiol. 177:13-15.

7. Nahas, G. G., and H. M. Cavert. 1957. Cardiac depressant effect of $\mathrm{CO}_{2}$ and its reversal. Am. J. Physiol. 190:483-491.

8. Rose, C. E., J. A. Althaus, D. L. Kaiser, E. D. Miller, and R. M. Carey. 1983. Acute hypoxemia and hypercapnia: increase in plasma catecholamines in conscious dogs. Am. J. Physiol. 245:H924-H929.

9. Gowdey, C. W., and Y. J. Patel. 1964. Responses to adrenaline and noradrenaline in cats during hypoxia, hyperventilation and hyperoxia. Arch. Int. Pharmacodyn. Ther. 150:67-84.

10. Page, I. H., and F. Olmsted. 1951. The influence of respiratory gas mixtures on arterial pressure and vascular reactivity in "normal" and hypertensive dogs. Circulation. 3:801-819.

11. Rose, C. E., R. J. Anderson, and R. M. Carey. 1984. Antidiuresis and vasopressin release with hypoxemia and hypercapnia in conscious dogs. Am. J. Physiol. 247:R127-R134.

12. Berns, A. S., R. J. Anderson, and K. M. McDonald. 1979. Effect 
of hypercapnic acidosis on renal water excretion in the dog. Kidney Int. 15:116-125.

13. Stalcup, S. A., J. S. Lipset, J. M. Woan, P. Levenberger, and R. B. Mellins. 1979. Inhibition of angiotensin converting enzyme activity in cultured endothelial cells by hypoxia. J. Clin. Invest. 63:966-976.

14. Anderson, R. J., C. E. Rose, A. S. Berns, A. L. Erickson, and P. E. Arnold. 1980. Mechanism of effect of hypercapnic acidosis on renin secretion in the dog. Am. J. Physiol. 238:F119-F125.

15. Kruszynski, M., B. Lammek, M. Manning, J. Seto, J. Haldar, and W. H. Sawyer. 1980. [1-( $\beta$-Mercapto- $\beta, \beta$-cyclopentamethylenepropionic acid), 2-(O-methyl)tyrosine]arginine-vasopressin and [1-( $\beta$-mercapto- $\beta, \beta$-cyclopentamethylenepropionic acid)]arginine-vasopressin, two highly potent antagonists of the vasopressor response to arginine vasopressin. J. Med. Chem. 23:364-368.

16. Andrews, C. E., and B. M. Brenner. 1981. Relative contributions of arginine vasopressin and angiotensin II to maintenance of systemic arterial pressure in the anesthetized water-deprived rat. Circ. Res. 48:254258.

17. Hamilton, W. F., J. W. Moore, J. M. Kinsman, and R. G. Spurling. 1932. Studies on the circulation. IV. Further analysis of the injection method, and of changes in hemodynamics under physiological and pathological conditions. Am. J. Physiol. 99:534-551.

18. Sealey, J. E., and J. H. Laragh. 1979. How to do a plasma renin assay. Cardiovas. Med. 2:1079-1092.

19. Anderson, R. J., R. G. Pluss, A. S. Berns, J. T. Jackson, P. E. Arnold, R. W. Schrier, and K. M. McDonald. 1978. Mechanism of effect of hypoxia on renal water excretion. J. Clin. Invest. 62:769-777.

20. Kissinger P., R. Riggin, R. Alcorn, and L. Rau. 1975. Estimation of catecholamines in urine by high performance liquid chromatography with electrochemical detection. Biochem. Med. 13:299-306.
21. Hjemdahl, P., M. Daleskog, and T. Kahan. 1979. Determination of plasma catecholamines by high performance liquid chromatography with electrochemical detection: comparison with a radioenzymatic method. Life Sci. 25:131-138.

22. Steele, R. G. D., and J. H. Torrie. 1960. Principles and Procedures of Statistics. McGraw-Hill Book Co., New York. 99-160.

23. Schwartz, J., and I. A. Reid. 1983. Role of vasopressin in blood pressure regulation in conscious water-deprived dogs. Am. J. Physiol. 244:R74-R77.

24. Schwartz, J., and I. A. Reid. 1981. Effect of vasopressin blockade on blood pressure regulation during hemorrhage in conscious dogs. Endocrinology. 109:1778-1780.

25. Levens, N. R., A. E. Freedlender, M. J. Peach, and R. M. Carey. 1983. Control of renal function by intrarenal angiotensin II. Endocrinology. 112:43-49.

26. Claybaugh, J. R., and L. Share. 1972. Role of the renin-angiotensin system in the vasopressin response to hemorrhage. Endocrinology. 90:453-460.

27. Houck, P. C., M. J. Fiksen-Olsen, S. L. Britton, and J. C. Romero. 1983. Role of angiotensin and vasopressin on blood pressure of ganglionic blocked dogs. Am. J. Physiol. 244:H115-H120.

28. Bonjour, J. P., and R. L. Malvin. 1970. Stimulation of ADH release by the renin-angiotensin system. Am. J. Physiol. 218:1555-1559.

29. Tagawa, H., A. J. Vander, J. Bonjour, and R. L. Malvin. 1971. Inhibition of renin secretion by vasopressin in unanesthetized sodiumdeprived dogs. Am. J. Physiol. 220:949-951.

30. Hammill, S. C., W. W. Wagner, L. P. Latham, W. W. Frost, and J. V. Weil. 1979. Autonomic cardiovascular control during hypoxia in the dog. Circ. Res. 44:569-575. 